\title{
Comparative analysis of the characteristics of atmospheric pollution in Beijing before and after the APEC conference
}

\author{
X. Li \& Y. Wei \\ Beijing Energy Conservation and Environmental Protection Center, \\ P R China
}

\begin{abstract}
In recent years, the atmospheric pollution in Beijing has become increasingly serious. The municipal government has launched a series of scientific research programs to prevent and control air pollution. In order to guarantee good air quality during the APEC (Asia-Pacific Economic Cooperation) conference, strong environmental control measures were adopted in Beijing and surrounding areas, which successfully resulted in "APEC Blue". This paper is one of the key municipal scientific research projects, in which the air quality in Beijing was monitored throughout the APEC conference for the purpose of evaluating the effectiveness and operability of the coordinated environmental control measures.

In this paper, the correlation between $\mathrm{PM}_{2.5}$ and $\mathrm{PM}_{10}$ and their variation rules are summarized through all-weather monitoring of $\mathrm{NO}_{2}, \mathrm{NO}, \mathrm{O}_{3}, \mathrm{PM}_{2.5}$ and $\mathrm{PM}_{10}$ during the APEC conference. In addition, the photochemical reaction mechanism and major influencing factors in Beijing are revealed by comparative analysis of the $\mathrm{NO}_{2}, \mathrm{NO}$ and $\mathrm{O}_{3}$ concentration variation trend. The characteristics of atmospheric pollution and major pollution factors in Beijing are clarified through statistical analysis of the monitoring data. This paper gives us an insight into the smog in Beijing and provides an important basis for the municipal government to adopt corresponding prevention and control measures.

Keywords: atmospheric pollution in Beijing, PM 2.5, photo-chemical smog, APEC.
\end{abstract}

\section{Research background}

In recent years, the atmospheric pollution in Beijing has become increasingly serious. In 2013, there were 176 days with good air quality in Beijing, accounting 
for $48.2 \%$; and 58 days with serious pollution, accounting for $15.9 \%$ of the year. The average annual concentration of $\mathrm{PM}_{2.5}$ stood at 89.5 micrograms/cubic meter, much higher than the national standard of 35 micrograms/cubic meter. For this reason, the municipal government launched a series of scientific research programs to prevent and control air pollution. In order to guarantee the good air quality during the APEC conference, strong environmental control measures were adopted in Beijing and surrounding areas, which successfully resulted in "APEC Blue".

\section{Data and method}

The data of $\mathrm{PM}_{2.5}$ and $\mathrm{PM}_{10}$ were obtained from the Monitor Center of Beijing Municipal Environmental Protection Bureau, which were collected by automatic acquisition system from 16 districts in Beijing using a cutting sample technique.

The data of $\mathrm{NO}, \mathrm{NO}_{2}$ were obtained by EC9841B on-line Nitric oxide automatic monitor and the data of $\mathrm{O}_{3}$ were obtained by EC9810B on-line Ozone automatic monitor from Beijing MAX environmental instrument company. The monitors were placed outside of Beijing Energy Conservation and Environmental Protection Center from October 25th to November 26th, 2014.

\section{Analysis of the atmospheric pollution characteristics in Beijing}

\subsection{Analysis of $\mathbf{P M}_{2.5}$ source in Beijing}

Comparative analysis of $\mathrm{PM}_{2.5}$ sources in different years is conducted based on the data released by the Monitor Center of Beijing Municipal Environmental Protection Bureau.

See Figure 1(a), (b), (c) for comparison of analytical data concerning $\mathrm{PM}_{2.5}$ sources in Beijing in 2012 [1], 2013 [2] and during APEC in 2014 [3].

The years 2013 and 2014 were crucial for Beijing to stringently carry out for Clean Air Action Plan of Beijing Municipality. It was also in this period that APEC conference was held. Beijing over-fulfilled the task assigned in the action plan ahead of time by implementing important projects like limiting coal burning, motor vehicle fuel reduction, pollution control and emission reduction, dust suppression etc. Meanwhile, joint action was taken inside the 600-kilometer circle around Beijing to shut down, suspend, merge, transform coal-burning plants, to eliminate old motor vehicles, to limit vehicles on road, to suppress dust etc., so that the air quality improved remarkably in Beijing and surrounding areas.

Breakdown analysis of $\mathrm{PM}_{2.5}$ sources in Beijing in different periods indicates that the contribution of motor vehicles to $\mathrm{PM}_{2.5}$ increased from $22.2 \%$ in 2012 to $31 \%$ in 2013, and that the figure doubled to reach $47.3 \%$ during APEC in 2014, which shows vehicle emissions remained the major sources of air pollutants. In fact, the total pollutant emissions by motor vehicles in the city have declined under the impact of environmental measures such as eliminating vehicles that fail to meet the European No.1 standard for exhaust emissions, raising gasoline and 
emission standards. However, the more dramatic reduction of emissions caused by coal burning, industrial production and dust etc. lead to increasingly higher proportion of vehicle emissions. Therefore, reduction of vehicle emissions has to be given more prominence.

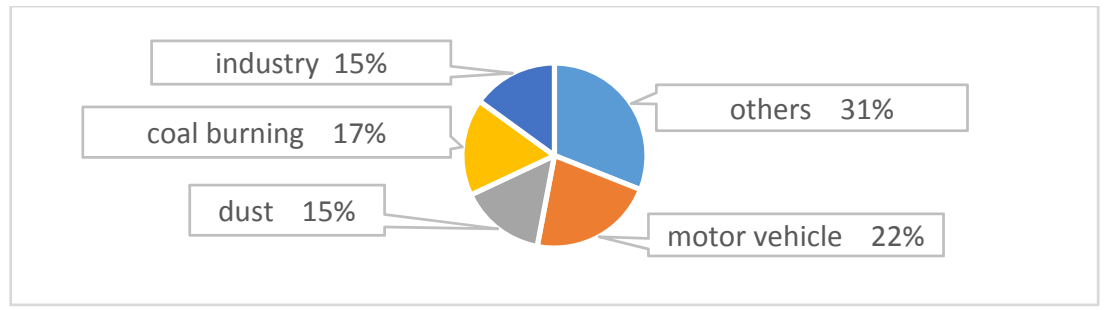

(a)

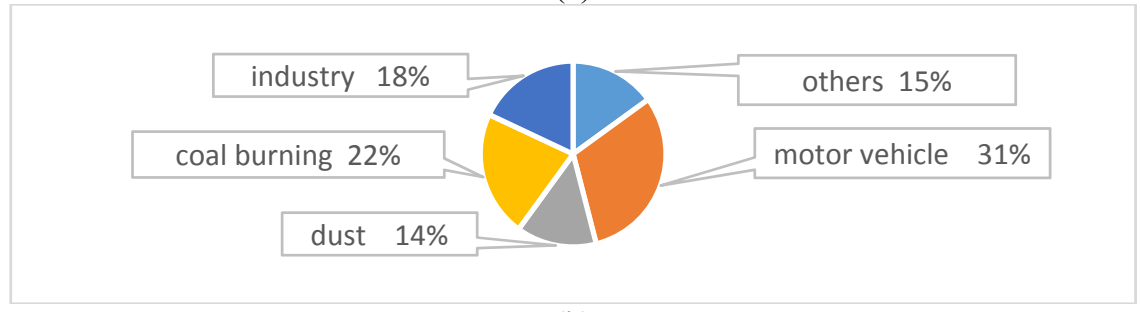

(b)

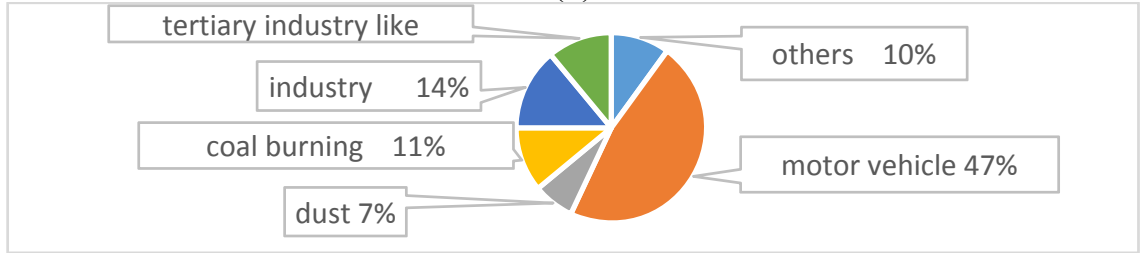

(c)

Figure 1: (a) Analytical chart of $\mathrm{PM}_{2.5}$ sources in Beijing in 2012; (b) analytical chart of $\mathrm{PM}_{2.5}$ sources in Beijing in 2013; (c) analytical chart of $\mathrm{PM}_{2.5}$ sources during APEC in Beijing in 2014.

\subsection{Analysis of $\mathbf{P M}_{2.5}$ composition}

See Figure 2 for the main components of $\mathrm{PM}_{2.5}$ in the air in Beijing [4].

Comprehensive analysis of $\mathrm{PM}_{2.5}$ composition and sources in Beijing shows two distinctive features: First, secondary particles have great influence as the dominant components of $\mathrm{PM}_{2.5}$. Secondary particles refer to the gaseous pollutants emitted from pollution sources, including contaminants like $\mathrm{NO}_{x}, \mathrm{SO}_{2}, \mathrm{NH}_{3}, \mathrm{VOC}_{\mathrm{s}}$ which are generated through complicated physical and chemical reactions in the atmosphere. Organics, nitrate, sulphate, ammonium salt in $\mathrm{PM}_{2.5}$ belong to secondary particles, accounting for $70 \%$ of $\mathrm{PM}_{2.5}$ mass. In case of serious pollution, secondary particles are the main cause for increased concentration of $\mathrm{PM}_{2.5}$. Second, ammonia nitrogen and organics are main pollutants in $\mathrm{PM}_{2.5}$. 
According to the comprehensive analysis of pollutant emission from pollution sources in cities, motor vehicles not only directly emit organics (OM) and element carbon (EC) etc., but also emit gaseous pollutants like Volatile Organic Compounds $\left(\mathrm{VOC}_{\mathrm{s}}\right)$ and nitrogen oxide $\left(\mathrm{NO}_{\mathrm{X}}\right)$, of which $\mathrm{VOC}_{\mathrm{s}}$ and $\mathrm{NO}_{\mathrm{X}}$ are important raw materials for the reaction to generate organics and nitrate in secondary particles of $\mathrm{PM}_{2.5}$. They are also important catalysts to increase atmospheric oxidation. Data suggests that the ratio of nitrate to sulphate in the air in Beijing was 0.6 in 2013, while the same ratio was 1.05 in 2014. The content of nitrate has far exceeded that of sulphate in the air. This figure corresponds to the increasing contribution of motor vehicles to emissions in the analysis of local $\mathrm{PM}_{2.5}$ sources.

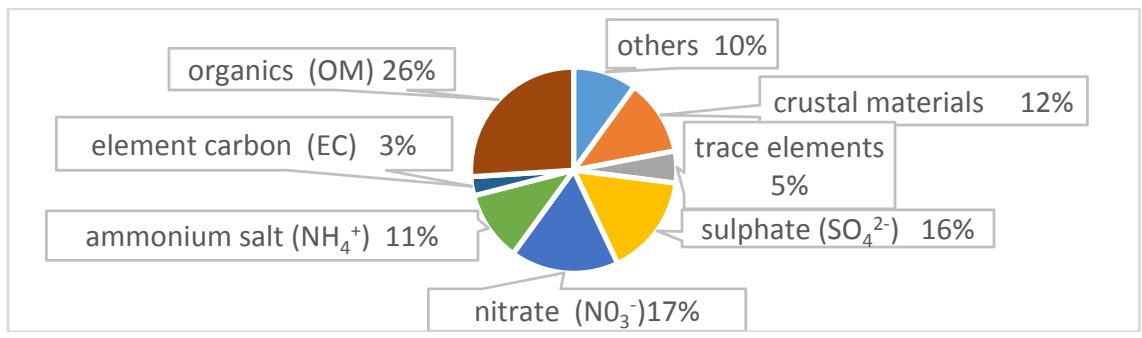

Figure 2: $\quad$ Mass percent of main $\mathrm{PM}_{2.5}$ components in Beijing in 2013.

\subsection{Correlation analysis of $\mathbf{P M}_{10}$ and $\mathbf{P M}_{2.5}$ in Beijing}

The change of monthly average $\mathrm{PM}_{10}$ and $\mathrm{PM}_{2.5}$ (unit: $\mu \mathrm{g} / \mathrm{m}^{3}$ ) in Beijing between December 2013-November 2014 is shown in Figure 3.

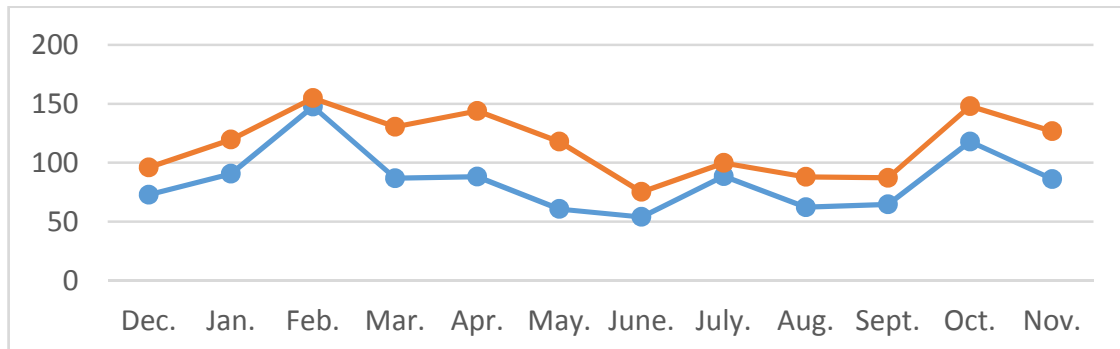

Figure 3: Monthly averages of $\mathrm{PM}_{10}$ and $\mathrm{PM}_{2.5}$ between December 2013 and November 2014.

It can been seen that the monthly average of $\mathrm{PM}_{10}$ was greater than that of $\mathrm{PM}_{2.5}$ between December 2013 and November 2014; the monthly average of $\mathrm{PM}_{10}$ and $\mathrm{PM}_{2.5}$ showed the same trend of change; the monthly average of $\mathrm{PM}_{10}$ was much greater than that of $\mathrm{PM}_{2.5}$ between March and May. The heaviest pollution took place in February and October; the monthly average of $\mathrm{PM}_{10}$ exceeded or approximated $150 \mu \mathrm{g} / \mathrm{m}^{3}$. In particular, the average values of $\mathrm{PM}_{10}$ and $\mathrm{PM}_{2.5}$ in 
February, 2014 were $155 \mu \mathrm{g} / \mathrm{m}^{3}$ and $148 \mu \mathrm{g} / \mathrm{m}^{3}$ respectively, which were close to each other.

Further analysis of the daily $\mathrm{PM}_{2.5} / \mathrm{PM}_{10}$ ratio $\rho$ (see Figure 4) shows that $\rho$ was greater than 1 on five days, namely, concentration of $\mathrm{PM}_{2.5}$ was higher than that of $\mathrm{PM}_{10}$, with maximum $\rho=2.08$, which indicates that $\mathrm{PM}_{2.5}$ in the air was the dominant factor of pollution, that $\mathrm{PM}_{10}$ took second place in terms of effect. It proves that primary pollutants took up a small percentage in case of serious air pollution, while secondary pollutants were the dominant factors of pollution.

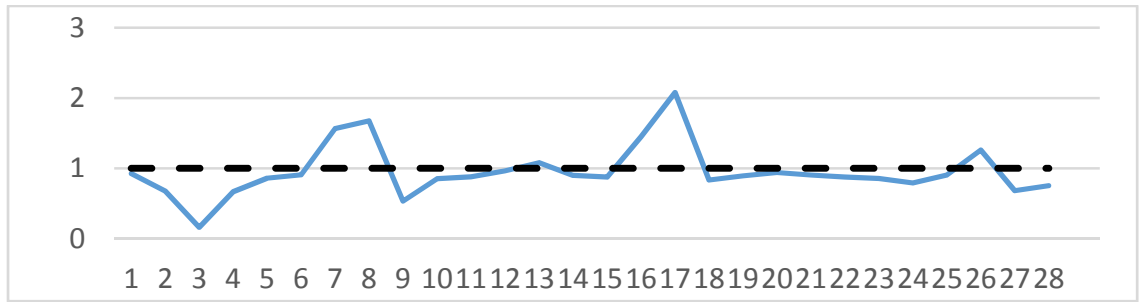

Figure 4: Daily $\mathrm{PM}_{2.5} / \mathrm{PM}_{10}$ ratios in February 2014.

See Figure 5 for the monthly $\mathrm{PM}_{2.5} / \mathrm{PM}_{10}$ ratio between December 2013 and November 2014.

It can been seen from Figure 5 that between December 2013 and November 2014, the maximum $\mathrm{PM}_{2.5} / \mathrm{PM}_{10}$ ratio occurred in February, $\rho_{\mathrm{Feb} .}=0.96$, approximating 1.0, indicating the equal role of $\mathrm{PM}_{10}$ and $\mathrm{PM}_{2.5}$ in terms of pollution effect. The minimum $\rho$ occurred in May, indicating that $\mathrm{PM}_{10}$ was the dominant factor of pollution and that $\mathrm{PM}_{2.5}$ caused less pollution. The $\rho$ value was low from March to May, indicating the air pollution in Beijing in spring is characterized by a higher concentration of $\mathrm{PM}_{10}$ and a lower concentration of $\mathrm{PM}_{2.5}$. The particle pollutants in the air are big in size. As it is dry in spring, factors like dust have greater influence on air pollution.

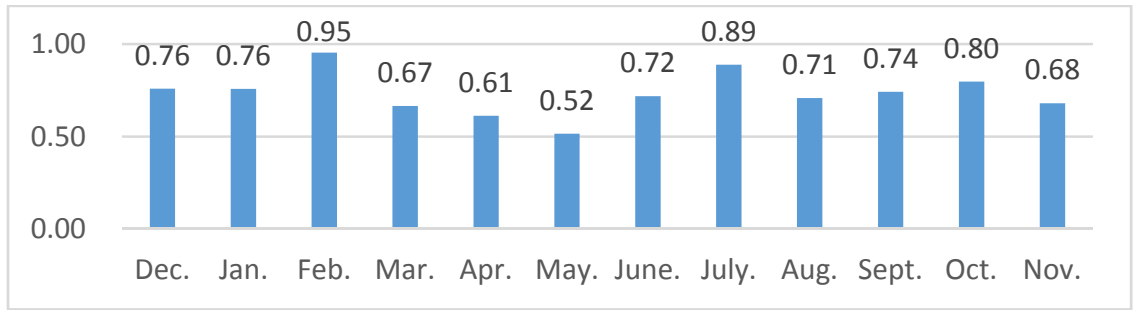

Figure 5: The monthly $\mathrm{PM}_{2.5} / \mathrm{PM}_{10}$ ratios between December 2013 and November 2014.

To further illustrate the change in composition of the air pollutants in Beijing, the $\mathrm{PM}_{2.5}$ and $\mathrm{PM}_{10}$ data of the year 2010 is analyzed in a comparative way in this paper. In 2010, the $\mathrm{PM}_{2.5} / \mathrm{PM}_{10}$ ratio in Beijing was generally less than 0.5, with 
only few data slightly higher than 0.5 , which showed high concentration of $\mathrm{PM}_{10}$ and low concentration of $\mathrm{PM}_{2.5}$ in air pollutants; environmental air quality was relatively clean; the pollution was characterized by large amounts of sand and dust flying from the ground; there were more primary pollutants and photochemical reaction was not the main cause for pollutants.

The air pollution in Beijing in 2014 was quite different from that in 2010 in terms of characteristics. Figure 5 shows the monthly $\mathrm{PM}_{2.5} / \mathrm{PM}_{10}$ ratio $\rho$ was greater than 0.5 throughout the year; the $\rho$ value reached 2.68 on July 31 st 2014; $\mathrm{PM}_{10}$ averaged $72.0 \mu \mathrm{g} / \mathrm{m}^{3}$ daily, while $\mathrm{PM}_{2.5}$ averaged $193.0 \mu \mathrm{g} / \mathrm{m}^{3}$ daily, indicating low concentration of $\mathrm{PM}_{10}$ and high concentration of $\mathrm{PM}_{2.5}$, which proves that primary pollutants, dust flying in the air were not the main cause for atmospheric pollution. Under strong sunshine in summer, the gaseous pollutants emitted from pollution sources generate secondary pollutants through photochemical reactions etc., which are the main components of $\mathrm{PM}_{2.5}$. At present, the atmospheric pollutants in Beijing have more complicated and diversified composition due to a series of photochemical smog reactions.

\section{4 $\mathrm{PM}_{2.5}$ and $\mathrm{NO}_{2}$ correlation analysis}

$\mathrm{NO}_{2}$ is one of the most active pollutants in the atmosphere. It is also an important factor which causes the formation of $\mathrm{PM}_{2.5}$. In order to better understand the role of $\mathrm{NO}_{2}$ in the formation of $\mathrm{PM}_{2.5}, \mathrm{PM}_{2.5}$ values and $\mathrm{NO}_{2}$ concentration values between December 2013 and November 2014 are analyzed on daily basis in this paper in cases of good air quality, slight and moderate pollution and heavy, serious pollution. See Figures 6-8 for the average daily $\phi=\mathrm{PM}_{2.5} / \mathrm{NO}_{2}$ under the three meteorological conditions.

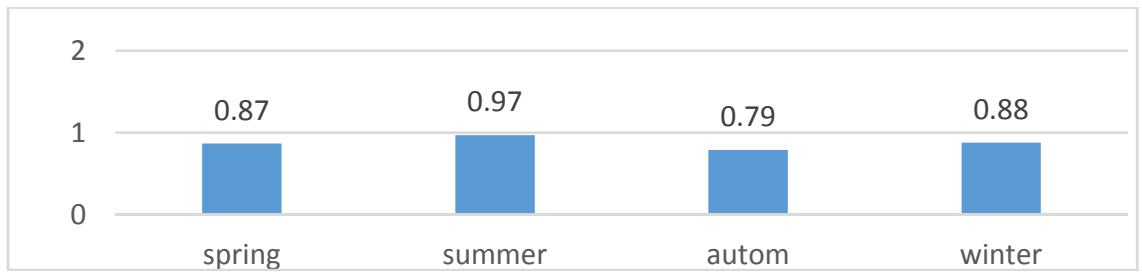

Figure 6: $\quad \mathrm{PM}_{2.5} / \mathrm{NO}_{2}$ comparison chart in the case of good air quality.

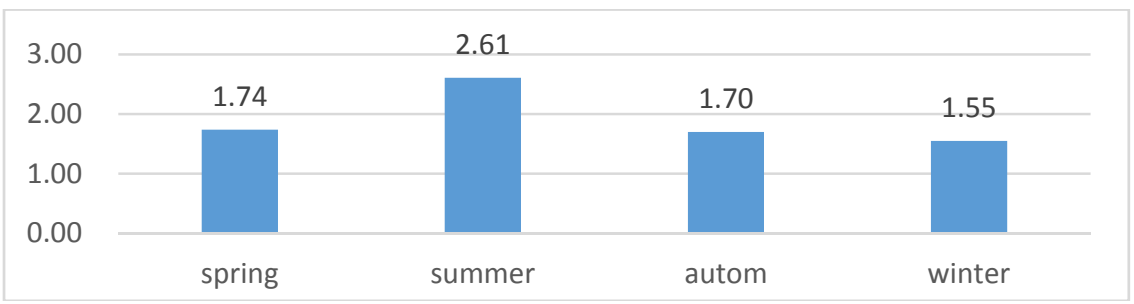

Figure 7: $\quad \mathrm{PM}_{2.5} / \mathrm{NO}_{2}$ comparison chart in the case of slight and moderate pollution. 


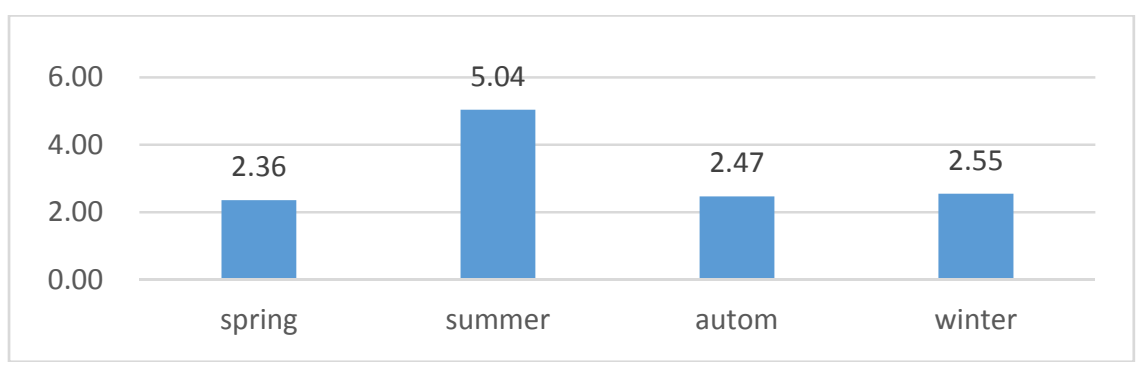

Figure 8: $\quad \mathrm{PM}_{2.5} / \mathrm{NO}_{2}$ comparison chart in the case of heavy, serious pollution.

The analysis of $\mathrm{PM}_{2.5} / \mathrm{NO}_{2}$ ratios in cases of different air quality shows that $\mathrm{PM}_{2.5} / \mathrm{NO}_{2}$ ratio varies greatly with different pollutant concentrations. In the case of good air quality, $\mathrm{PM}_{2.5} / \mathrm{NO}_{2}$ ratio averaged 0.88 annually, indicating $\mathrm{NO}_{2}$ was the main factor of pollution; in the case of slight and moderate pollution, $\mathrm{PM}_{2.5} / \mathrm{NO}_{2}$ ratio averaged 1.90 annually, indicating that $\mathrm{PM}_{2.5}$ concentration was about twice that of $\mathrm{NO}_{2}$ and that $\mathrm{PM}_{2.5}$ became the dominant factor; in the case of heavy, serious pollution, $\mathrm{PM}_{2.5} / \mathrm{NO}_{2}$ ratio averaged 3.10 annually, indicating that $\mathrm{PM}_{2.5}$ concentration was about three times that of $\mathrm{NO}_{2}$, and that $\mathrm{PM}_{2.5}$ was the main factor of pollution. It can be seen from the comparison chart that the $\mathrm{PM}_{2.5} / \mathrm{NO}_{2}$ ratio in summer was apparently higher than that in the other three seasons under all meteorological conditions, which indicates that conversion from $\mathrm{NO}_{2}$ to $\mathrm{HNO}_{3}$, PAN and organic acid was expedited under strong sunshine, making secondary pollutants generated through photochemical reactions the main components of $\mathrm{PM}_{2.5}$.

The comprehensive analysis of the data shows that photochemical reactions are the main cause of $\mathrm{PM}_{2.5}$ pollution in Beijing. The reaction mechanism to generate photo-chemical smog is significantly correlated with the actual monitoring values.

\section{Analysis of air quality monitoring data during the APEC conference 2014}

\subsection{Analysis of $\mathrm{NO}, \mathrm{NO}_{2}$ and $\mathrm{O}_{3}$ correlation during the APEC conference}

The rare "APEC Blue" occurred in Beijing for the strong measures to guarantee the clean air in Beijing and surrounding areas during APEC conference. Beijing energy conservation and environmental protection center collected data every hour from 6:00 to 23:00 in the period from October 25th to November 26th 2014 to monitor and analyze the $\mathrm{NO}, \mathrm{NO}_{2}$ and $\mathrm{O}_{3}$ index.

See Figure 9(a), (b), (c) for the change trend of average $\mathrm{O}_{3}, \mathrm{NO}, \mathrm{NO}_{2}$ concentration in seven days before, during and after the APEC conference. 


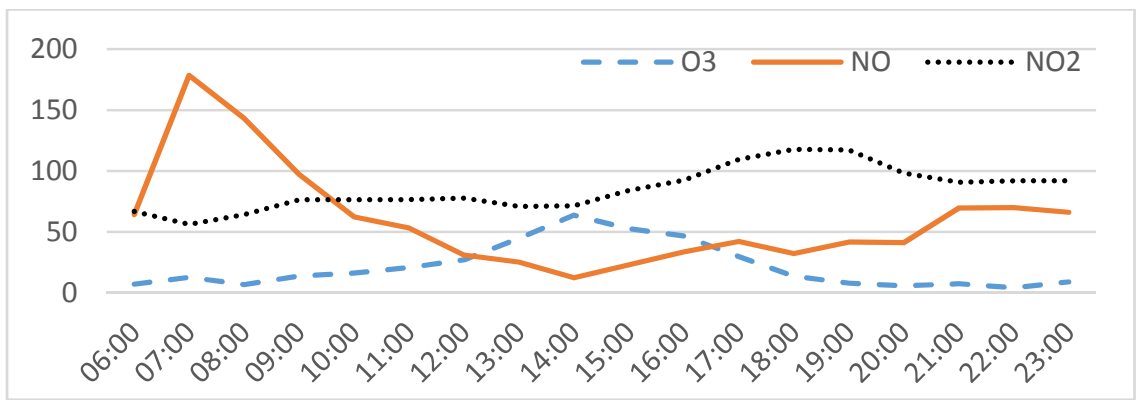

(a)

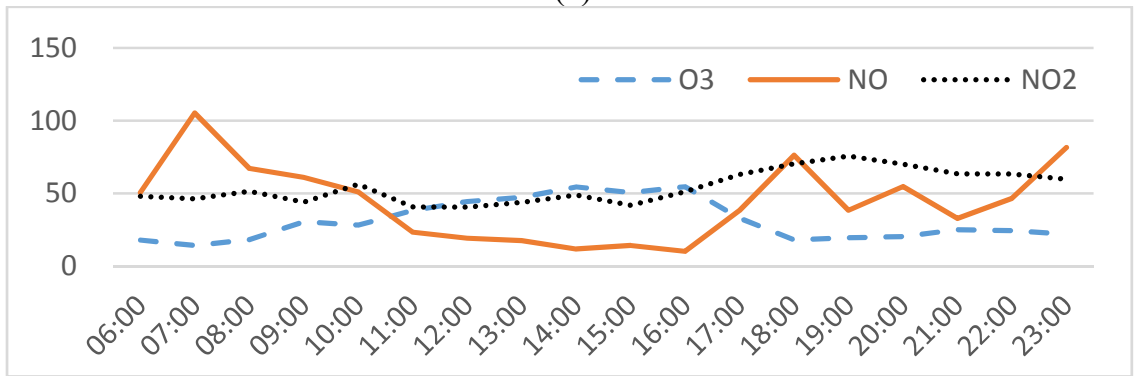

(b)

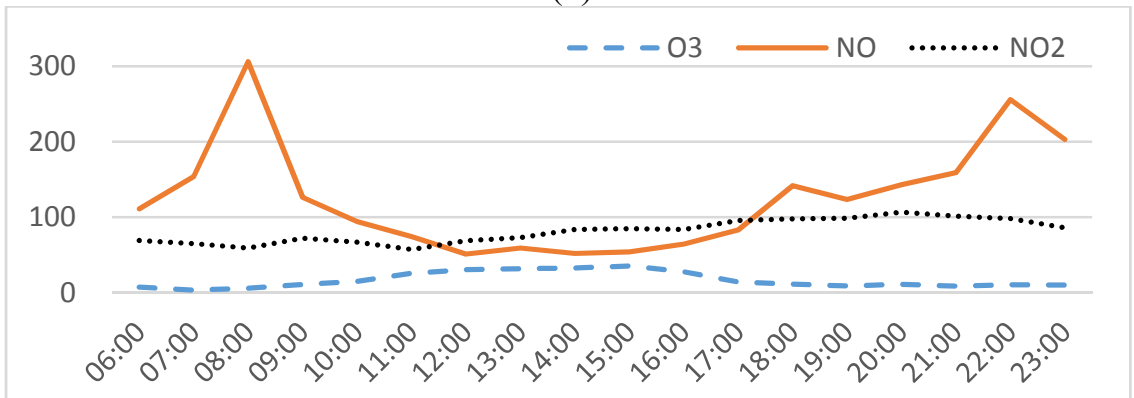

(c)

Figure 9: The change trend of characteristic pollutant concentration (a) before the APEC conference (October 25th-31st); (b) during the APEC conference (November 5th-11th) and (c) after the APEC conference (November 13th-19th).

The concentrations of $\mathrm{NO}$ and $\mathrm{NO}_{2}$ showed significant changes before, during and after APEC Conference as a result of measures such as limiting vehicles on road, reducing industrial emissions. The changing relationship between $\mathrm{NO}, \mathrm{NO}_{2}$, $\mathrm{O}_{3}$ corresponded to the phenomena of typical photochemical smog experiment. NO was characterized by considerable correlation with the traffic flow. The highest NO concentration value occurred at rush hours in the morning, and reached its peak at 7:00-8:00. The peak value of NO concentration reached $164 \mu \mathrm{g} / \mathrm{m}^{3}$ and $306 \mu \mathrm{g} / \mathrm{m}^{3}$ respectively before (October 25th-31st) and after APEC (November 13th-19th), while the same value was lowered to $105 \mu \mathrm{g} / \mathrm{m}^{3}$ due to measures like 
limiting vehicles on road during APEC conference (November 5th-11th), which proves that traffic emission is one of the direct and sensitive factors that influence $\mathrm{NO}$ concentration value. NO was involved in photochemical reaction afterwards, causing the drop of its concentration value at 10:00-11:00. Meanwhile, the $\mathrm{NO}_{2}$ concentration value began to rise. The NO concentration value dropped to the lowest level of the day at 12:00-15:00, and rose slightly at 17:00-18:00 (due to traffic flow), during which the $\mathrm{NO}_{2}$ concentration value increased steadily, indicating that the generation of $\mathrm{NO}_{2}$ by $\mathrm{NO}$ through photochemical reaction played a dominant role. At 20:00 or so, the $\mathrm{NO}_{2}$ concentration value rose to the maximum of the day. Peak value of $\mathrm{NO}_{2}$ concentration reached $111 \mu \mathrm{g} / \mathrm{m}^{3}$ and $106 \mu \mathrm{g} / \mathrm{m}^{3}$ respectively before and after APEC, while the same value was lowered by $28 \%$ to $76 \mu \mathrm{g} / \mathrm{m}^{3}$ during APEC conference. At 23:00 afterwards, NO rose to the second peak value of the day with a concentration level lower than that in the morning, while the $\mathrm{NO}_{2}$ concentration value dropped significantly. The change trend of $\mathrm{O}_{3}$ concentration was opposite to that of $\mathrm{NO}$ and $\mathrm{NO}_{2}$, with the value during the conference apparently higher than that before and after the conference. The $\mathrm{O}_{3}$ concentration value was low in the morning, averaging $10 \mu \mathrm{g} / \mathrm{m}^{3}$ or so. It rose gradually with increasing sunshine and reached the maximum of $50 \mu \mathrm{g} / \mathrm{m}^{3}$ at 14:00-16:00 in the afternoon.

\subsection{Analysis of the $\mathrm{NO}, \mathrm{NO}_{2}$ and $\mathrm{O}_{3}$ change mechanism before, during and after the APEC conference}

The rules of change in concentration of the above three pollutants show prominent photochemical reactions in the atmosphere in Beijing, and NO in the air may be converted into $\mathrm{NO}_{2}$ through oxidation process, namely:

$$
\begin{aligned}
\mathrm{NO}+\mathrm{O}_{3} & \rightarrow \mathrm{NO}_{2}+\mathrm{O}_{2} \\
\mathrm{NO}+\mathrm{HO}_{2} \cdot & \rightarrow \mathrm{NO}_{2}+\mathrm{HO} .
\end{aligned}
$$

These reactions cause the gradual increase in $\mathrm{NO}_{2}$ concentration. Meanwhile, the following photochemical smog reactions [5] take place with increasing sunshine:

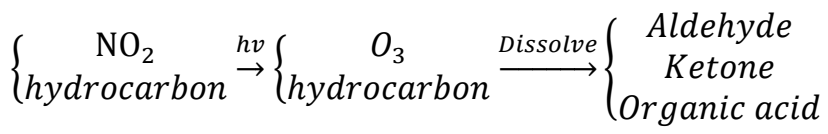

The generation of intermediate $\mathrm{O}_{3}$ enables the $\mathrm{O}_{3}$ concentration value to reach its peak at 14:00 in the afternoon, expediting the conversion from $\mathrm{NO}$ to $\mathrm{NO}_{2}$, whereas the reactions involving $\mathrm{NO}_{2}$ and radicals like $\mathrm{HO}, \mathrm{HO}_{2}$ 'consumes some $\mathrm{NO}_{2}$, causing less noticeable change in $\mathrm{NO}_{2}$ concentration in the middle of the day. The reactions are as follows:

$$
\begin{gathered}
\mathrm{NO}_{2}+\mathrm{HO} \cdot \rightarrow \mathrm{HNO}_{3} \\
\mathrm{NO}_{2}+\mathrm{HO}_{2} \cdot \rightarrow \mathrm{HNO}_{2}+\mathrm{O}_{2}
\end{gathered}
$$

The $\mathrm{O}_{3}$ concentration value during APEC was apparently higher than that before and after APEC, indicating that the concentration of pollutants like aldehyde, ketone and organic acid decreased due to lowering of $\mathrm{NO}$ and $\mathrm{NO}_{2}$ 
concentration in the air. The consumption of $\mathrm{O}_{3}$ decreased accordingly, causing higher $\mathrm{O}_{3}$ concentration.

In order to compare the changes in pollutant concentrations in the atmospheric environment in Beijing before, during and after the APEC conference, the maximum (max), minimum (min) and average values of $\mathrm{NO}_{2}, \mathrm{NO}$ and $\mathrm{O}_{3}$ in the three periods are listed in table 1 .

Table 1: Comparison of $\mathrm{NO}_{2}, \mathrm{NO}$ and $\mathrm{O}_{3}$ monitoring data before, during and after the APEC conference.

\begin{tabular}{|c|c|c|c|c|c|c|}
\hline \multicolumn{2}{|c|}{} & $\begin{array}{c}\text { Before } \\
\text { APEC } \\
\left(\mu \mathrm{g} / \mathrm{m}^{3}\right)\end{array}$ & $\begin{array}{c}\text { After } \\
\text { APEC } \\
\left(\mu \mathrm{g} / \mathrm{m}^{3}\right)\end{array}$ & $\begin{array}{c}\text { Average value } \\
\text { before and } \\
\text { after APEC } \\
\left(\mu \mathrm{g} / \mathrm{m}^{3}\right)\end{array}$ & $\begin{array}{c}\text { During } \\
\text { APEC } \\
\left(\mu \mathrm{g} / \mathrm{m}^{3}\right)\end{array}$ & $\begin{array}{c}\text { Ratio } \\
\text { of } \\
\text { change } \\
(\%)\end{array}$ \\
\hline \multirow{3}{*}{$\mathrm{NO}$} & Max & 163.59 & 306.16 & 234.88 & 105.29 & -55.2 \\
\cline { 2 - 8 } & Min & 15.99 & 51.17 & 33.58 & 10.07 & -70.0 \\
\cline { 2 - 8 } & $\begin{array}{c}\text { Average } \\
\text { value }\end{array}$ & 63.76 & 125.34 & 94.55 & 44.35 & -53.1 \\
\hline \multirow{3}{*}{$\mathrm{NO}_{2}$} & Max & 111.04 & 106.86 & 108.95 & 75.61 & -30.6 \\
\cline { 2 - 8 } & Min & 56.37 & 57.43 & 56.9 & 40.56 & -28.7 \\
\cline { 2 - 8 } & $\begin{array}{c}\text { Average } \\
\text { value }\end{array}$ & 83.05 & 81.68 & 83.37 & 54.37 & -34.8 \\
\hline \multirow{3}{*}{$\mathrm{O}_{3}$} & Max & 46.87 & 35.70 & 41.29 & 54.66 & 32.4 \\
\cline { 2 - 8 } & Min & 4.23 & 3.64 & 3.94 & 14.16 & 259.4 \\
\cline { 2 - 7 } & $\begin{array}{c}\text { Average } \\
\text { value }\end{array}$ & 18.38 & 16.89 & 17.64 & 31.16 & 76.6 \\
\hline
\end{tabular}

It can been from table 1 that the reduction of the $\mathrm{NO}$ pollutant was higher than that of the $\mathrm{NO}_{2}$ pollutant during APEC, that the average value of NO during APEC decreased by $53.1 \%$ in comparison with the average value before and after APEC, and the minimum value of NO during APEC was down by $70 \%$ compared with the average value before and after APEC, and that the content of NO pollutant in the air was lowered significantly.

The average value of $\mathrm{NO}_{2}$ pollutant during APEC decreased by $34.8 \%$ in comparison with the average value before and after APEC; both the maximum value and the minimum value decreased by about $30 \%$, indicating that the content of $\mathrm{NO}_{2}$ pollutant in the air was reduced by $30 \%$.

The average content of $\mathrm{O}_{3}$ in the air during APEC showed significant growth of $76.6 \%$ compared with that before and after APEC.

The above data shows that the environmental protection projects which implemented in Beijing and surrounding areas, including limiting coal burning, motor vehicle fuel economy, dust suppression, shutting down pollution enterprises, suspending or limiting production of coal-burning plants, decreased the pollutants in air significantly. The reduction of nitrogen oxides in the air weakened the relaying photochemical reactions, namely, the photolysis reaction with hydrocarbon and the reaction with $\mathrm{NO}_{2}$ to generate aldehyde, ketone, organic acid 
and peroxyacetyl nitrate (PAN) were reduced significantly, while the $\mathrm{O}_{3}$ concentration in the air during APEC increased greatly in comparison with that before and after APEC due to less consumption in intermediate reactions.

\section{Main conclusions}

1. $\mathrm{PM}_{10}$ and $\mathrm{PM}_{2.5}$ correlation analysis shows that the characteristics of atmospheric pollutants in Beijing changed greatly between 2010 and 2014. In 2010, $\mathrm{PM}_{2.5} / \mathrm{PM}_{10}$ ratio was less than 0.5 most of the time (except on a few days), indicating that $\mathrm{PM}_{10}$ is the main pollutant in the air, whereas the monthly $\mathrm{PM}_{2.5} / \mathrm{PM}_{10}$ ratio averaged 0.71 in 2014 , and the $\mathrm{PM}_{2.5} / \mathrm{PM}_{10}$ ratio was greater than 1.0 on more than $10 \%$ of the days with the maximum ratio reaching 2.68 , making $\mathrm{PM}_{2.5}$ become the main factor of air pollution in Beijing.

2. The correlation analysis of $\mathrm{PM}_{2.5}$ and $\mathrm{NO}_{2}$ monitoring data in 2014 shows that a remarkable positive correlation relationship exists between $\mathrm{PM}_{2.5}$ and $\mathrm{NO}_{2}$ concentration. The $\mathrm{PM}_{2.5} / \mathrm{NO}_{2}$ ratio in summer was apparently higher than that in spring, autumn and winter. The increasing sunshine strengthens the conversion from $\mathrm{NO}_{2}$ to $\mathrm{PM}_{2.5}$. When the pollutant concentration in the air changed, namely, in cases of good air quality, slight and moderate pollution and heavy, serious pollution, average $\mathrm{PM}_{2.5} / \mathrm{NO}_{2}$ ratios were $0.88,1.90$ and 3.11 respectively, which indicates that the photochemical reactions were intensified with increasing $\mathrm{NO}_{2}$ concentration, resulting in poor air quality.

3. During the APEC conference, the implementation of environmental protection measures in Beijing and surrounding areas significantly reduced $\mathrm{NO}, \mathrm{NO}_{2}$ concentration, weakened photochemical smog reactions and greatly improved air quality. There is no noticeable correlation between the change trend of $\mathrm{NO}, \mathrm{NO}_{2}$ and $\mathrm{O}_{3}$ and their concentration values. Motor vehicle emissions contributed more to the $\mathrm{PM}_{2.5}$ during the APEC conference, becoming the main $\mathrm{PM}_{2.5}$ pollution source. The change rules of NO concentration highly corresponded to the traffic flow.

\section{References}

[1] Beijing Municipal Bureau of Environmental Protection, 2012 Beijing Municipal Environment Bulletin, p. 4.

[2] Beijing Municipal Bureau of Environmental Protection, 2013 Beijing Municipal Environment Bulletin, p. 5.

[3] Beijing Municipal Bureau of Environmental Protection, 2014 Beijing Municipal Environment Bulletin, p. 5.

[4] Peng, Y. D., The analysis of formation factors and control measures of smog in Beijing, Journal of Engineering Studies, 5(3), pp. 233-239, 2013.

[5] Wang X. L., Cui Y., Environmental Chemistry, p. 35, 2013. 